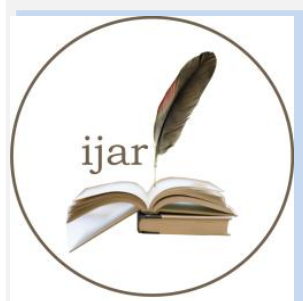

ISSN NO. 2320-5407

\section{Journal Homepage: - www.journalijar.com INTERNATIONAL JOURNAL OF ADVANCED RESEARCH (IJAR)}

Article DOI: $10.21474 / \mathrm{IJAR} 01 / 1432$

DOI URL: http://dx.doi.org/10.21474/IJAR01/1432
INTERNATIONAL JOURNAL OF ADVANCED RESEARCH (JJAR)

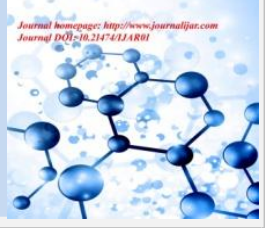

RESEARCH ARTICLE

\title{
A CASE REPORT ON PULMONARY ALVEOLAR MICROLITHIASIS.
}

"Dr. Suman Kumar Jagaty, Dr. Pravati Dutta, Dr. Rekha Manjhi and Dr. Sudarsan Pothal. Department of pulmonary medicine, VSS Medical College, Burla, Odisha, India.

\section{Manuscript Info}

Manuscript History

Received: 12 June 2016

Final Accepted: 19 July 2016

Published: August 2016

Key words:-

\section{Abstract}

Background: Pulmonary alveolar microlithiasis(PAM) is a rare inborn error of calcium metabolism with unknown etiology and familial association in which concretions composed of calcium and phosphorus collect in alveolar spaces ${ }^{1}$.It was first named in 1933 by Puhr.

Case Report: A 42 year old male non smoker,weaver presenting with 6 months history of fever,cough with mild expectoration and dyspnea on exertion was diagnosed as miliary tuberculosis by a local physician for which he was given antitubercular treatment for 3 months but his symptoms was not improving for which he came to outdoor.He had no past history of any chronic diseases or any chronic drug use.His general physical examination was unremarkable with vitals being normal.Respiratory system examination revealed bilateral vesicular breath sound with fine inspiratory crackles in axillary,infraaxillary infrascapular area.

Investigation: His laboratory parameters and Pulmonary function test were normal and sputum was negative for acid fast bacilli.His ABG parameter and Echocardiography report were normal.Chest X-ray shows bilateral diffuse micronodular shadows (sand-storm pattern) predominant in middle and lower zones and disease free pleura as black pleura line.HRCT thorax shows diffuse calcified micronodular opacities with lower lobe and subpleural predominance and septal thickening.BAL Fluid shows characterstic calcified spherules.

Discussion: PAM is due to inborn error of calcium metabolism confined to lung and leading to deposition of calcified spherules in alveolar spaces ${ }^{2}$.It is inherited as autosomal recessive condition diagnosed during third through fifth decades $^{3}$.Most patients are asymptomatic.Some may present with cough,progressive dyspnea,haemoptysis.Inspiratory crackles, clubbing and signs of cor pulmonale seen in advanced cases. Chest X-ray may show diffuse micronodular shadows(sand storm pattern) and black pleura line(disease free pleura appears as black line).HRCT may show micronodular opacities and subpleural predominance.PFT may show restrictive defect ${ }^{4}$.Transbronchial lung biopsy is confirmative ${ }^{5}$.Currently there is no effective treatment is available except lung transplantation.

Conclusion: Pulmonary alveolar microlithiasis being a rare disease with unknown etiology has burdened the patient with unnecessary doses of anti-tubercular treatment because of its resemblance to miliary 
tuberculosis on chest X-ray.Patients due to delayed diagnosis ultimately progress to end stage lung disease necessitating lung transplantation.So attempt for earlier diagnosis and finding the etiology is all that needed.

References: 1.Murray \& Nadel's textbook of respiratory medicine- $5^{\text {th }}$ ed.1462-63. 2. Sosman MC, Dodd D, Jones WD, et al. The familial occurrence of pulmonary alveolar microlithiasis. Am J Roentgenol1957; 77: 947-1012. 3. Jönsson ÅL, Simonsen U, Hilberg O, Bendstrup E. Pulmonary alveolar microlithiasis:Two case reports and review of the literature. Eur Respir Rev 2012;21:249-56. 4.Sharma SK. Sharma S, Mukhopadhyaya S, Padhye AK Vijayaraghavan M. Pulmonary alveolar microlithiasis - function and exercise report of three cases with pulmonary studies. Indian J Chest Dis Allied Sci 1992; 34:205-215.5. Kang HW, Kim TO, Oh IJ, Kim YI, Lim SC, Choi YD, et al. A case of pulmonary alveolar microlithiasis. J Korean Med Sci 2011;26:1391-3.

Copy Right, IJAR, 2016,. All rights reserved.

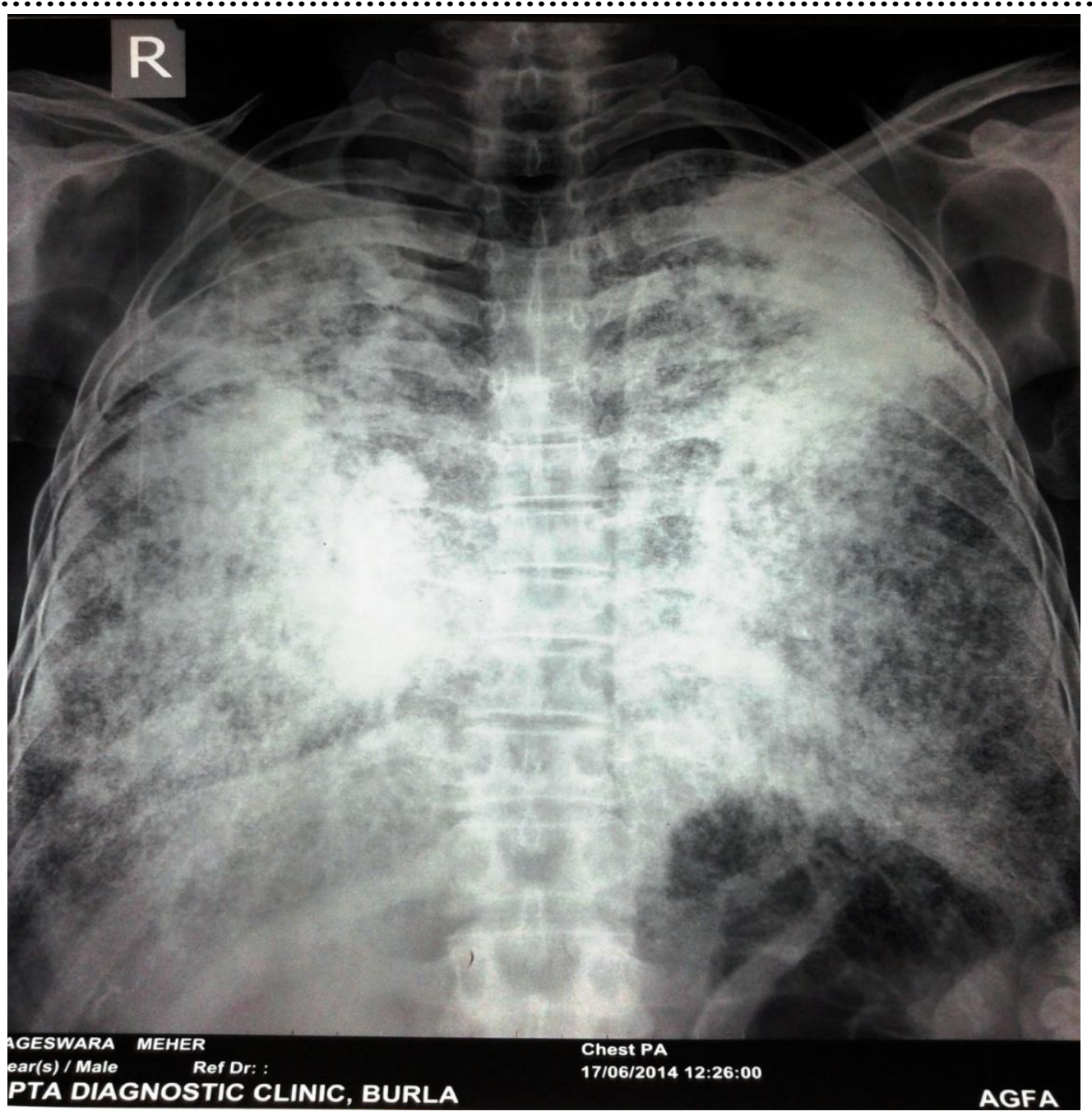

Chest X-ray showing B/L diffuse micronodular calcific shadows (sandstorm appearance) 


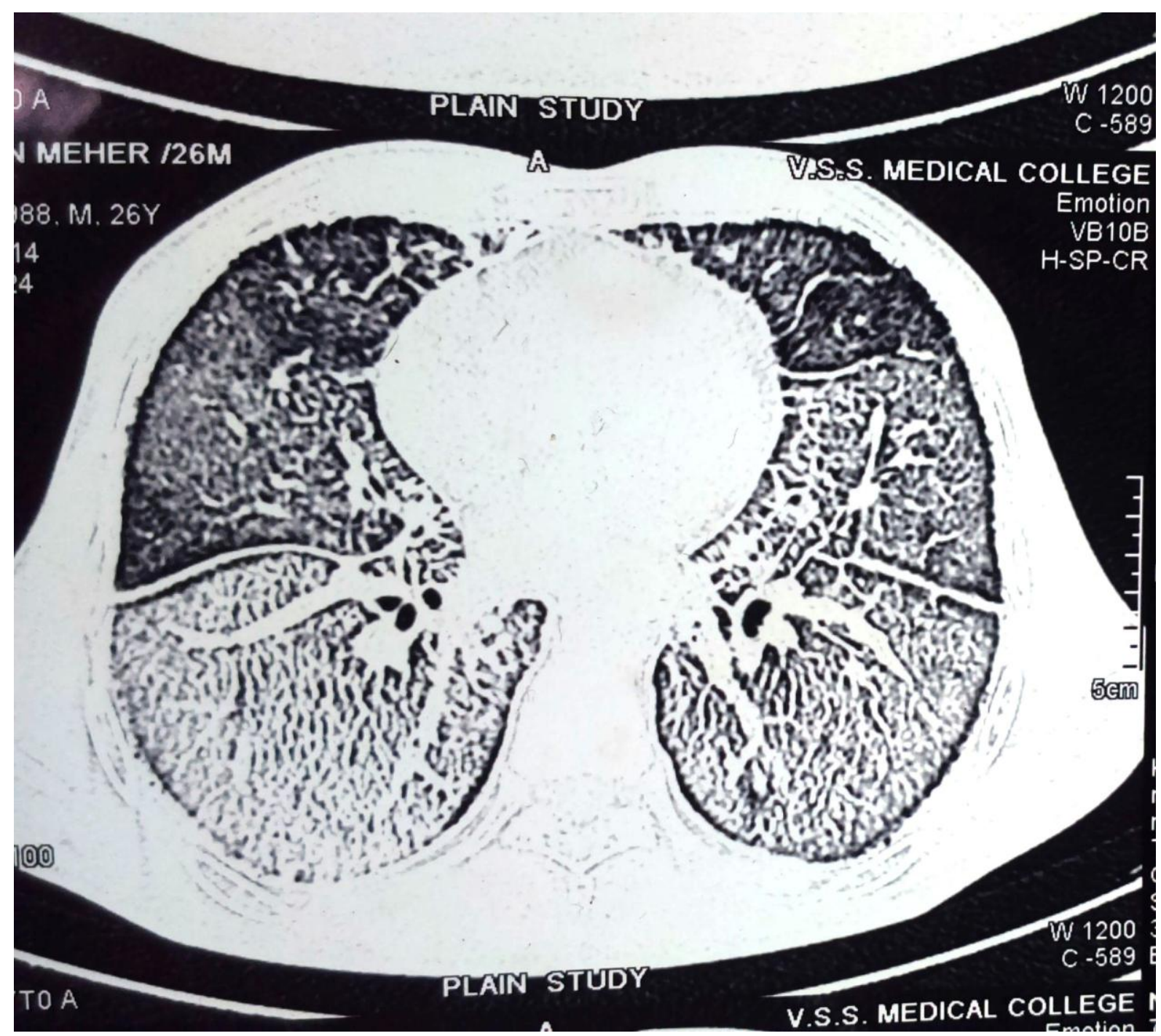

HRCT of thorax showing B/L diffuse calcified micronodular opacities with lower lobe and subpleural predominance and septal thickening 


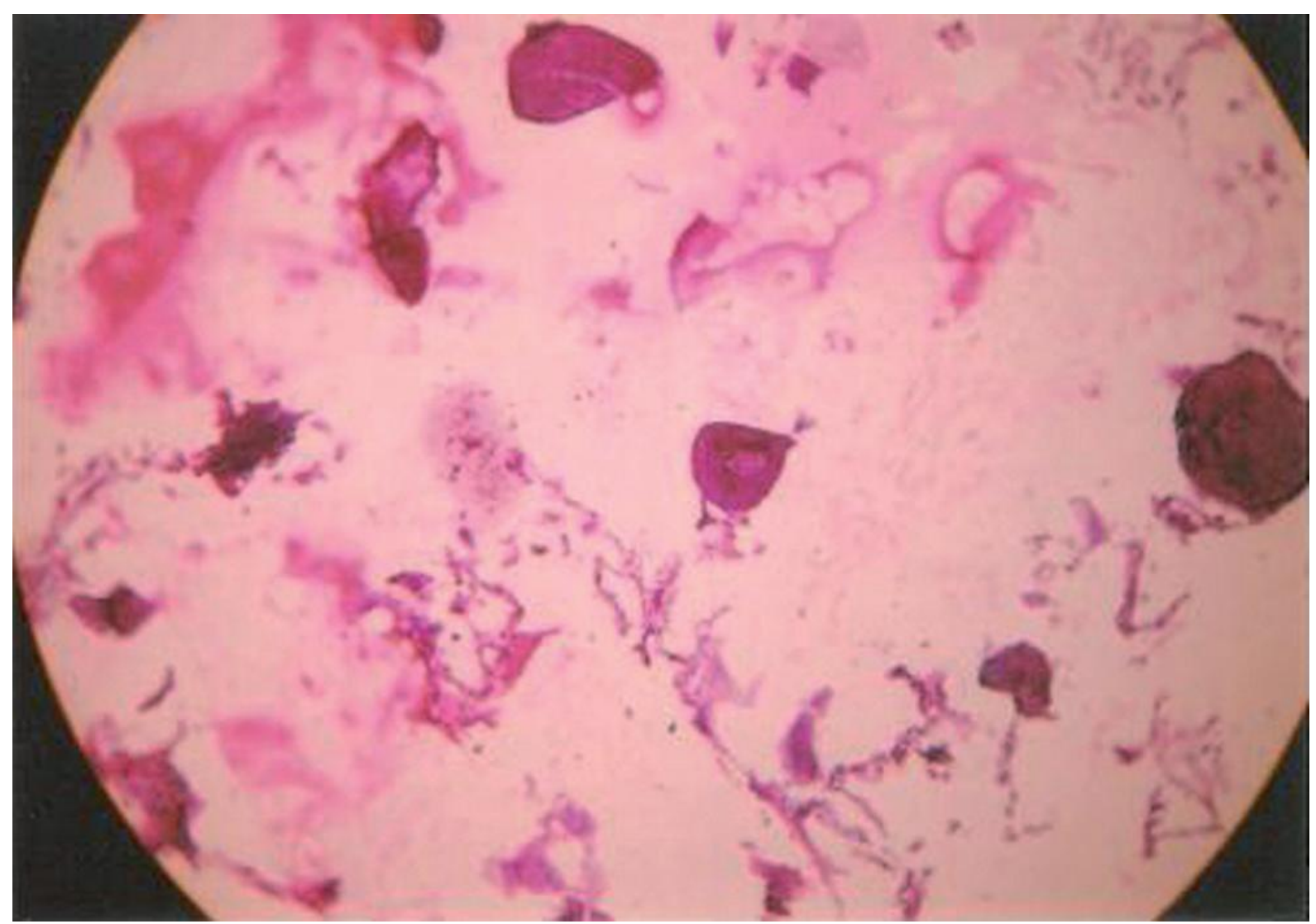

Bronchoscopic biopsy demonstrating intraalveolar and intraparenchymal concentric lamellar bodies. 